\title{
Treatment of acid mine drainage with coal fly ash in a jet loop reactor pilot plant
}

\author{
Rosicky Methode Kalombe ${ }^{\mathrm{a}, \mathrm{c}, *}$, Tunde Victor Ojumu ${ }^{\mathrm{a}}$, Vinny Ndjate Katambwe ${ }^{\mathrm{a}}$, Michael Nzadi ${ }^{\mathrm{a}}$, \\ Denzil Bent ${ }^{\mathrm{b}}$, George Nieuwouldt ${ }^{\mathrm{b}}$, Godfrey Madzivire ${ }^{\mathrm{d}, \mathrm{e}}$, John Kevern ${ }^{\mathrm{c}}$, Leslie Felicia Petrik ${ }^{\mathrm{b}}$ \\ ${ }^{a}$ Cape Peninsula University of Technology, Department of Chemical Engineering, PO Box 1906, Bellville, Cape Town, Western Cape 7535, South Africa \\ ${ }^{\mathrm{b}}$ University of the Western Cape, Department of Chemistry, Private Bag X17, Bellville 7535, South Africa \\ ${ }^{\mathrm{c}}$ University of Missouri-Kansas City, Department of Civil and Mechanical Engineering, 5110 Rockhill, Kansas City, MO 64110, United States \\ ${ }^{\mathrm{d}}$ Council for Geoscience, Water and Environment Unit, 208 Pretoria Street, Silverton, Pretoria 0184, South Africa

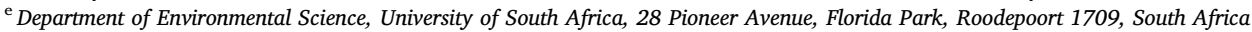

\section{A R T I C L E I N F O}

\section{Keywords:}

Acid mine drainage

Neutralization

Fly ash

Jet loop reactor pilot plant

\begin{abstract}
A B S T R A C T
A $1500 \mathrm{~L}$ batch jet loop reactor pilot plant was designed, constructed, and evaluated for performance in the treatment of acid mine drainage (AMD) using coal fly ash with a view to optimize its operation and generate performance data. Results showed that concentration of major contaminants (sulfate, $\mathrm{Al}, \mathrm{Fe}, \mathrm{Ca}, \mathrm{Mg}$ ), and minor contaminants in the treated AMD can be significantly lowered (between one and four orders of magnitude) compared to the raw AMD. It was shown that the one-step treatment process recovered at least $66.6 \%$ $(728.56 \mathrm{~kg}$ ) of treated water depending on the degree of dewatering required for slurry pumping. The energy consumption of $2.655 \mathrm{~kW}$ used for pumping indicated that an oversized centrifugal pump (15 kW capacity) was used for the neutralization cycle, as only a small fraction of the pump capacity was utilized. The treated water met the target water quality range (TWQR) limit for agricultural irrigation in South Africa. The analysis of the solid residue shows its suitability for backfilling of mine voids or for making geopolymer such that AMD treatment with fly ash results in a zero discharge process. The treatment process offers a cradle-to-cradle solution to acid mine drainage and coal fly ash.
\end{abstract}

\section{Introduction}

The growing worldwide demand for electricity has led to an increase in the use of coal. Consequently, large amounts of waste are generated in the form of coal combustion by-products such as fly ash and AMD (Blissett and Rowson, 2012). In South Africa, the main coal reserves are found in the Emalahleni, Highveld, and Ermelo coalfields in Mpumalanga province. The current reserves of coal are estimated at between 15 and 55 billion tons, and these reserves are expected to increase the mining of coal in the next decades (Mushia et al., 2016). South African coal power stations produced 32.6 billion tons of coal ash from 2016 to 2017 ("National Assembly Question No. 3383 Nw3776e," 2018). The waste coal fly ash is extremely alkaline with pH greater than 12 (Musyoka, 2009; Madzivire et al., 2010) and requires to be safely disposed of as it is classified as hazardous waste when placed in dumpsites. The disposal of fly ash necessitates large areas to be used as dumpsites, which may lead to encroachment on agricultural land. Other challenges related to fly ash disposal include high dumping costs and potential leaching of toxic elements and salts from the dumped fly ash into the surrounding soil or groundwater (Nyale et al., 2013). Therefore, it is of great importance to invest more in reuse or beneficiation of fly ash to optimize its utilization and increase its value, thus subsequently minimize environmental challenges associated with its disposal (Sear, 2009).

The mining sector is one of the major contributors to the development of the South African economy. However, mining activities are also associated with the pollution of the environment due to the release of highly acidic water, often termed acid mine drainage (AMD) (Oberholster et al., 2010). AMD in the Witwatersrand goldfields of South Africa has reached a crisis point. This problem is not only limited to the goldfields in Gauteng. It is also a huge problem in the Mpumalanga coalfields. The few freshwater resources in Mpumalanga

\footnotetext{
* Corresponding author.

E-mail addresses: Rmk7mb@mail.umkc.edu (R.M. Kalombe), OjumuT@cput.ac.za (T.V. Ojumu), novavinny3@gmail.com (V.N. Katambwe), mnzadi@gmail.com (M. Nzadi),2856000@myuwc.ac.za (D. Bent), org2020@gmail.com (G. Nieuwouldt), gmadzivire@gmail.com (G. Madzivire), kevernj@umkc.edu (J. Kevern), lpetrik@uwc.ac.za (L.F. Petrik).
} 
including the Vaal and Olifants rivers are threatened by AMD containing a high concentration of sulfate ions, $\mathrm{Al}, \mathrm{Fe}$, and Mn (Madzivire et al., 2015). The protection of water resources has become a fundamental policy concern as well as a driver for continued economic growth and service delivery to South Africa (Oberholster et al., 2010).

Usually, AMD is treated with limestone and/or lime to raise the $\mathrm{pH}$ and simultaneously precipitate metals (Gazea et al., 1996; Potgieter et al., 2006). However, using liming agents alone makes the treatment of AMD more costly. Petrik et al. (2003) have proven that without adding liming agents, fly ash alone can be involved in the neutralization of various types of AMD. These studies were further investigated by many other authors such as Gitari et al. (2006); and Valente and Gomes (2009). Throughout these studies, different ratios of AMD to fly ash were used at bench scale. The results showed that the addition of fly ash to AMD could increase the $\mathrm{pH}$ from 2 to 3 to neutral $\mathrm{pH}$ or above. The mixing rate influenced the change in $\mathrm{pH}$ and water composition. The $\mathrm{pH}$ was found to have a significant effect on the decrease of potentially toxic metal concentrations and the removal of sulfate ions could be enhanced by the addition of a small amount of lime and aluminum hydroxide especially in the case of $\mathrm{Ca}$ and $\mathrm{Mg}$ sulfate rich AMD (Madzivire et al., 2010). Successful treatment of AMD was achieved as reported in these studies. The treated water met the target water quality range (TWQR) permits for irrigation and agriculture, according to the Department of Water and Sanitation of South Africa. However, this treatment approach necessitates the use of a high amount of fly ash. This means that large storage tanks were needed to store the coal fly ash at the treatment plant. Also, the optimum liquid to solid ratio of 3:1 needed when using an overhead stirrer mixing technique produced a thick slurry that required special paste pumps. This makes the upscaling of this process challenging and reducing the amount of water recovered after treatment.

Based on these observations, superior mixing with a jet loop reactor was used as one way to reduce the amount of coal fly ash that was needed for the treatment of mine water. The jet loop reactor promotes a faster reaction rate by exerting a higher mass transfer rate and mixing intensity compared to a continuous stirred tank reactor. A high mixing rate in a jet loop reactor occurs due to hydrodynamic cavitation and impingement processes that occur inside the reactor (Vadapalli et al., 2008; Madzivire et al., 2015). Hydrodynamic cavitation is created by pressure variations due to the changes in the geometry of the system through which the solution is flowing. Pressure variation occurs when a solution flows through a small orifice, thereby causing the pressure and kinetic energy to drop. The turbulence produces an area of greatly reduced fluid pressure causing the vaporization of the liquid, forming a cavity. Hydrodynamic cavitation can be controlled by adjusting the flow rate, pressure, and orifice size. The intense mixing of the reactants results in the formation of metastable phases causing the kinetics to be increased. A very important aspect of this type of process is that it can be scaled up easily.

Madzivire et al. (2015) incorporated the jet loop reactor to an $80 \mathrm{~L}$ pilot plant using a centrifugal pump (1.5 kW). The optimum condition obtained for treating circumneutral mine water consisted of a liquid to solid ratio of 5 , and addition of $0.25 \% \mathrm{w} / \mathrm{v}$ of lime, and $83.2 \mathrm{~g}$ of $\mathrm{Al}$ $(\mathrm{OH})_{3}$. Using this pilot plant, about $80 \%$ of sulfate was removed and metals concentration in the raw water was significantly decreased to trace levels. The product water recovered using this system could be used in agriculture and process industries or can be made potable by ion-exchange or zeolite adsorption to remove the remaining trace elements followed by the correction of $\mathrm{pH}$ to between 6 and 9 through bubbling of $\mathrm{CO}_{2}$. The solid residues of the process can be used to produce commercially viable products namely geopolymers (Vadapalli et al., 2008; Nyale et al., 2013), zeolites (Petrik et al., 2003; Somerset et al., 2005) and, can also be used to backfill the mine voids and thus prevent further AMD formation, offering a cradle-to-cradle solution (Petrik et al., 2003; Somerset et al., 2005; Gitari et al., 2006; Madzivire et al., 2015) to the problematic waste (coal fly ash and AMD). The limitation of this process is that the chemical composition and mineralogy of fly ash varies, and the quality of AMD also varies. This could affect the neutralization reaction. Therefore, operating conditions may have to be modified and process controls at full-scale treatments are vital. These findings motivated the upscaling of the process from $80 \mathrm{~L}$ to a larger pilot plant of $1500 \mathrm{~L}$.

The present study is expected to generate for the first time the performance data of a jet loop reactor pilot plant for the treatment of mine water with fly ash. The idea is to provide optimum conditions for the efficient operation of the pilot plant at a scale suited for the treatment of a large volume of mine water with coal fly ash, thus complementing previous studies on this subject matter. The success of thisapproach could change the perception of mine water and fly ash as waste in the environment and improve the economics of coal mining.

\section{Materials and methods}

In this study, the waste materials used were AMD from a coal mine and fly ash collected from two different coal power stations in Mpumalanga Province, South Africa.

\subsection{Description of analytical techniques}

The Mpumalanga coal-mining region in South Africa was chosen as the study area for this project. This is a suitable area as numerous AMD discharges and large coal-fired power stations are present. This source of AMD typically has a $\mathrm{pH}$ of about 2 (Petrik et al., 2003).

The inductively coupled plasma-optical emission spectroscopy (ICPOES) was used to determine the elemental composition of raw and treated AMD. The samples were filtered using a micro-membrane filter of $0.45 \mu \mathrm{m}$ to remove suspended particles. The samples were diluted using a $2 \% \mathrm{HNO}_{3}$ aqueous solution at the ratio of $1: 10$ or $1: 100(\mathrm{~V} / \mathrm{V})$, depending on the concentration of elements to be analyzed. The samples were analyzed using a Varian 710-ES ICP-OES instrument which was calibrated using standards containing elements to be analyzed.

Ion chromatography (IC) was used to analyze the changes in anion concentration of the raw and treated AMD. The samples were filtered through $0.45 \mu \mathrm{m}$ nucleopore membrane filter paper and preserved at $4{ }^{\circ} \mathrm{C}$ until analysis was conducted. A Dionex DX-120 Ion Chromatograph with an AS40 automated sampler, ASRS- 300 suppresser, AS14 analytical column, AG14 guard column, and a conductivity detector was used for the analysis. The eluent used was a mixture of $3.5 \mathrm{mM} \mathrm{NaHCO}_{3}$ and $1.0 \mathrm{mM} \mathrm{Na} \mathrm{CO}_{3}$.

$\mathrm{X}$-ray Fluorescence (XRF) was used to determine the elemental composition of the as-received fly ash. For the major element analysis, each sample was dried at $110{ }^{\circ} \mathrm{C}$ overnight and was prepared as follows: $0.65 \mathrm{~g}$ of a sample and $5.60 \mathrm{~g}$ of a flux (consisting of $66.67 \% \mathrm{Li} 2 \mathrm{~B} 4 \mathrm{O} 7$, $32.83 \% \mathrm{LiBO} 2$, and $0.50 \% \mathrm{LiBr}$ ) were mixed, and the mixture was fused to a glass bead. The oxides of the major elements were determined using a Philips PW 1480 X-ray spectrometer. The spectrometer was fitted with a chromium tube, five analyzing crystals namely LIF 200, LIF 220, GE, PE, and PX, and the detectors being a combination gas-flow proportional counter and a scintillation detector. The gas-flow proportional counter uses P10 gas, which is a mixture of argon and methane at a 9:1 ratio.

\subsection{Treatment of acid mine drainage}

The $1500 \mathrm{~L}$ pilot plant was designed to improve the recovered water quality obtained at the bench scale where a solution of AMD and fly ash was mixed in a beaker using an overhead stirrer and at the $80 \mathrm{~L}$ scale where the same solution was mixed using a single jet loop reactor.

The $1500 \mathrm{~L}$ pilot plant in Fig. 1 represents the large scale design based upon the $80 \mathrm{~L}$ pilot plant (Madzivire et al., 2015). This pilot plant 


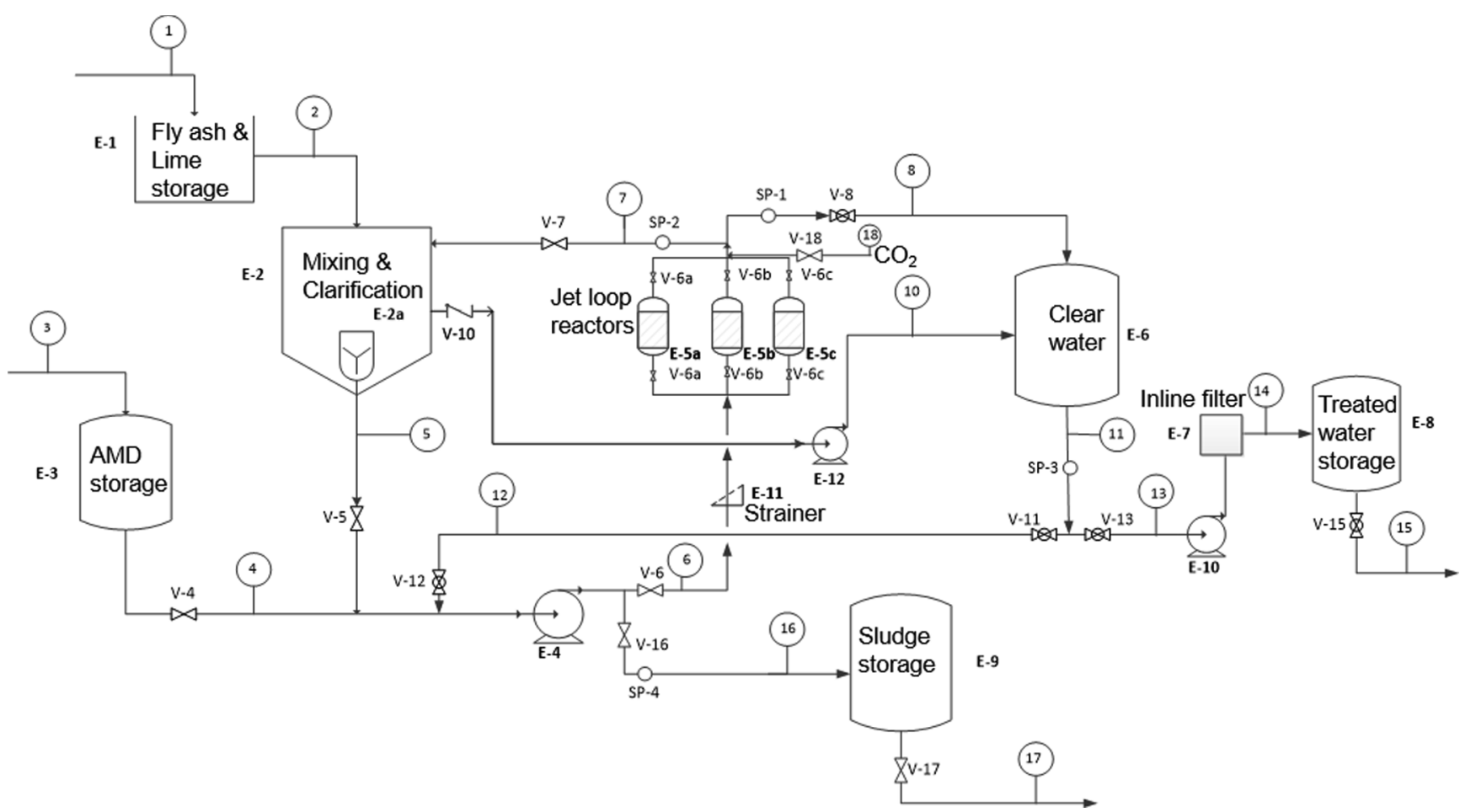

Fig. 1. Process flow diagram for the treatment of $\mathrm{AMD}$ with fly ash, lime and $\mathrm{Al}(\mathrm{OH})_{3}$ using the jet loop reactor pilot plant.

has a maximum capacity to treat $1500 \mathrm{~L}$ of mine water. The present investigation focused on the treatment of $1000 \mathrm{~L}$ of AMD. This pilot plant consists of a mixing and clarification tank, carbonation tank, slurry, water recovery tank, three jet loop reactors (orifice $10 \mathrm{~mm}$ diameter), pipework (50 mm diameter), and three pumps (15 $\mathrm{kW} \mathrm{AH}$ METAL fly ash pump, $0.75 \mathrm{~kW}$ PK 60 and $1.5 \mathrm{~kW}$ EBARA). The material of construction of the mixing and clarification tanks, fly ash bucket and sieve, pipework and fittings were SS304 and mild steel for the framework.

The $1500 \mathrm{~L}$ pilot plant was equipped with an automation system used for controlling and monitoring the process. The automated cycles consisted of seven stages:

Stage 1: filling the mixing and clarification tank with $1000 \mathrm{~L}$ of AMD;

Stage 2: acid neutralization and clarification;

Stage 3: settling of slurry and decanting clarified water;

Stage 4: carbonation;

Stage 5: discharge treated water from the carbonation tank;

Stage 6: slurry removal and cleaning of the mixing cycle; and

Stage 7: options for rinsing the pilot plant.

As depicted in Fig. 1, the operation of this jet loop reactor pilot plant consists mainly of neutralization and clarification (E-2), carbonation (E6), recovery of clean water (E-8), and collection of solid residues (E-9). The purpose of this pilot plant was to increase the $\mathrm{pH}$ of AMD, precipitate out metals in AMD and to decrease the sulfate concentration by mixing with fly ash, lime, and $\mathrm{Al}(\mathrm{OH})_{3}$. The pilot plant consisted of two steps;

1. Step 1 constituted of the mixing and clarification. This takes place when the mixture of AMD, fly ash, and lime was mixed in unit E-2 and through unit E-5 and allowed to settle in unit E-2. The clear water was pumped to the clear water tank (E-6).

2. Step 2 constituted of carbonation of the clear product water to bring down the $\mathrm{pH}$ to below 9 and precipitate calcium by sparging $\mathrm{CO}_{2}$ for about one minute as shown in Fig. 1. The collected solid residue was settled to a specific density and the supernatant water returned to the clear tank (carbonation tank).
In this study, the first experiment with the $1500 \mathrm{~L}$ pilot plant was performed using the optimum conditions obtained at $80 \mathrm{~L}$ pilot plant by Madzivire et al. (2015). This consisted of treating AMD with fly ash using the liquid to solid ratio of $5: 1$. This solution was mixed in the mixing tank and pumped through the jet loop reactors for $10 \mathrm{~min}$. Then, $2.5 \mathrm{~kg}(0.25 \%)$ of lime (w/v \%) was added to AMD and FA mixture to increase the $\mathrm{pH}$ to above 11 after mixing for about $150 \mathrm{~min}$. After 150 min $3.6 \mathrm{~kg}$ of $\mathrm{Al}(\mathrm{OH})_{3}$ was added to AMD, FA, and lime solution that were all simultaneously mixed in the tank and through the jet loop reactors. The mixture of AMD, fly ash, lime, and $\mathrm{Al}(\mathrm{OH})_{3}$ was circulating through the jet loop system for $20 \mathrm{~min}$, and then it was allowed to settle for $30 \mathrm{~min}$. After settling, clear water with a $\mathrm{pH}$ above 11 was pumped to the carbonation tank (E-6). The $\mathrm{pH}$ of the clear water was adjusted between 7 and 9 using $\mathrm{CO}_{2}$. The clear water was circulated from the carbonation tank through the jet loop reactor for an additional $10 \mathrm{~min}$. This experiment was performed for $180 \mathrm{~min}$ excluding the settling time; the samples were collected every $30 \mathrm{~min}$ for $\mathrm{pH}$ measurement, IC, and ICP-OES analysis.

\subsubsection{Optimization of the AMD to fly ash ratio}

Based on the $\mathrm{pH}$, IC and ICP-OES result obtained at $1500 \mathrm{~L}$ using these conditions (Madzivire et al., 2015) a further determination of the optimum liquid to solid (AMD to fly ash) ratio and amount of lime for the treatment of AMD using the jet loop reactor pilot plant at $1500 \mathrm{~L}$ was carried out. $\mathrm{pH}$ and sulfate levels were used as indicators to minimize both the use of chemical reagents and the operating time while improving the quality of AMD.

The ratios of liquid to solid of $5: 1,6: 1$, and $7: 1$ were used to treat AMD with fly ash from two different power stations in Mpumalanga province, South Africa. Throughout the experiment, the samples were collected every $10 \mathrm{~min}$ for $\mathrm{pH}$ and after $70 \mathrm{~min}$ for IC analysis. The optimum liquid to solid ratio was selected based on the $\mathrm{pH}$ level reached, high sulfate removal percentage, and quality of water recovered after mixing and clarification.

\subsubsection{Optimization of the use of lime}

When the optimum ratio of AMD to fly ash was obtained, the 
investigation of the optimum amount of lime ( $\mathrm{w} / \mathrm{v} \%$ of lime to AMD) to be added to the mixture of AMD and fly ash was carried out. The amount of lime was varied between $0.05 \%, 0.1 \%$, and $0.15 \%$. When the $\mathrm{pH}$ of the mixture of AMD and fly ash was raised to above 7, lime was added. The optimum amount of lime was selected based on the $\mathrm{pH}$ level, sulfate removal percentage, and the lowest quantity of lime used. The $\mathrm{pH}$ was measured every $10 \mathrm{~min}$ while the aliquot sample was collected after $110 \mathrm{~min}$ for IC analysis.

The raw AMD and treated water were filtered through a $0.45 \mu \mathrm{m}$ pore membrane filter paper using a manual pumping device. The filtered samples were divided into two portions for cation and anion analysis. The cation samples were preserved with three drops of concentrated $\mathrm{HNO}_{3}$ for approximately $100 \mathrm{~mL}$ of sample. Both cation and anion samples were stored at $4{ }^{\circ} \mathrm{C}$ until analysis for cations and anions using ICP-OES and IC, respectively (Petrik et al., 2003; Gitari et al., 2006; Madzivire et al., 2015).

\subsection{Material balance description}

A mass balance was used so as to quantify the amount of AMD and chemical reagents required as inputs as well as the treated water and solid residue recovered at the end of the process. The overall mass balance for a nonreactive process was performed according to Felder and Rousseau (2005) within the system boundary shown in Fig. 2. Inputs for calculation included $1000 \mathrm{~L}$ of AMD, $200 \mathrm{~kg}$ of fly ash, $2.5 \mathrm{~kg}$ of lime, and $3.6 \mathrm{~kg}$ of $\mathrm{Al}(\mathrm{OH})_{3}$ over the testing period of $180 \mathrm{~min}$.

The general material balance equations are as follows:

Accumulation $=$ input - output + generation - consumption

The calculations were performed assuming:

The system at a steady state which has no accumulation; therefore:

Input + generation $=$ Output + Consumption

The balanced quantity is total, there is no generation or consumption; therefore:

Input $=$ Output

The density ( $\rho$ ) of AMD of $1094 \mathrm{~kg} / \mathrm{m}^{3}$ was applied to determine the mass of AMD.

The compositions of the feed streams (M1 = AMD, M2 = powders) of the $1500 \mathrm{~L}$ batch pilot plant used during AMD treatment are shown in Table 1.

The moisture content was determined using the sludge. Three sludge samples were collected and weighed immediately and recorded as wet weight of the sample, these wet samples were dried to a constant
Table 1

Feed streams composition of the $1500 \mathrm{~L}$ batch pilot plant.

\begin{tabular}{llll}
\hline Input & Element & Mass $(\mathbf{k g})$ & Mass fraction \\
\hline M1 & AMD & 1094 & 1 \\
M2 & fly ash & 200 & 0.970 \\
& Al(OH) & 3.6 & 0.018 \\
& lime & 2.5 & 0.012 \\
& Total & 1300.1 & \\
\hline
\end{tabular}

weight at a temperature of $100{ }^{\circ} \mathrm{C}$ using an oven for $24 \mathrm{~h}$. The samples were allowed to cool. The cooled samples were weighed again and recorded as the dry weight of samples. The moisture content of the sample was calculated using equation (4):

$\% \mathrm{~W}=\left(\frac{\mathrm{A}-\mathrm{B}}{A}\right) \times 100$

Where, \%W: Percentage of moisture in the sample, A: Weight of wet sample (grams) and B: Weight of dry sample (grams)

\subsection{Energy balance description}

In addition to the mass balance, the other important quantity considered in the analysis of fluid flow was the energy balance or conservation of energy in this study. The conservation of energy calculation for fluid flowing from an open mixing tank through pump 1 (main pump) to the jet loop reactors was performed according to Brodkey and Hershey (1988); and Walas (1990). The calculations included the head loss $\left(\mathrm{H}_{\mathrm{L}}\right)$, head loss due to fittings $\left(\mathrm{H}_{\mathrm{V}}\right)$, head system $\left(\mathrm{H}_{\mathrm{P}}\right)$, fluid power, shaft power, and electrical power. The efficiency of the centrifugal pump and its motor was $40 \%$ and $89.5 \%$ respectively.

\section{Results and discussion}

\subsection{Characterization of $A M D$ and fly ash}

Table 2 shows the characterization of AMD using ICP-OES and IC. It was identified that AMD had a pH of 2.2, and had a significant content of $\mathrm{SO}_{4}{ }^{2-}, \mathrm{Al}, \mathrm{Mg}, \mathrm{Ca}$, and $\mathrm{Fe}$; as well as substantial amounts of $\mathrm{Mn}$ and $\mathrm{Na}$ as depicted in Table 2.

The elemental composition of the AMD showed that the AMD supplied for this study was relatively low in $\mathrm{Al}$ and $\mathrm{Fe}$, and had a relatively low sulfate content, unlike some of the prior work (Vadapalli et al., 2008; Gitari et al., 2008) and was relatively higher in $\mathrm{Ca}$ and $\mathrm{Mg}$

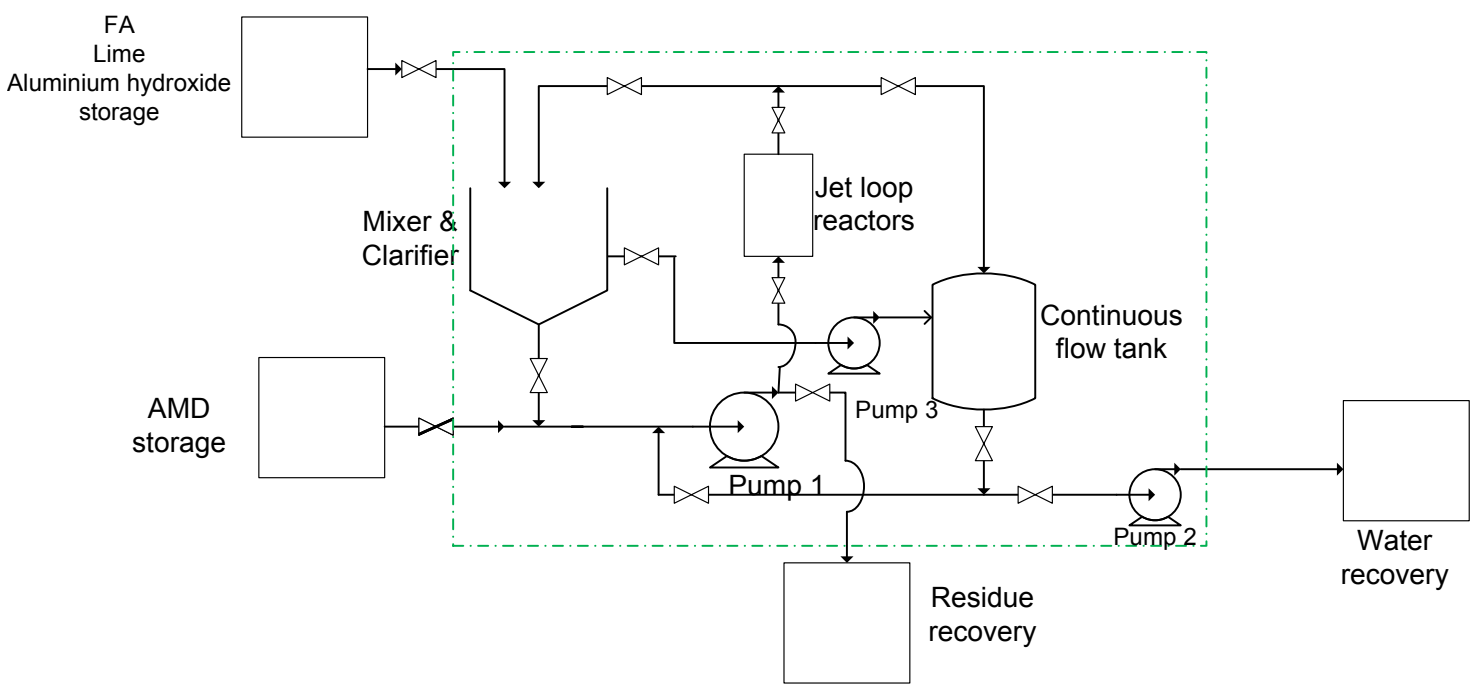

Fig. 2. Process boundary for material balance during AMD treatment. 
Table 2

\begin{tabular}{ll}
$\begin{array}{l}\text { Elemental composition } \\
\text { Mpumalanga. }\end{array}$ & of \\
\hline Parameter & Results \\
\hline $\mathrm{pH}$ & 2.2 \\
$\mathrm{Element}$ & $\mathrm{mg} / \mathrm{L}$ \\
$\mathrm{SO}_{4}{ }^{2-}$ & 2680 \\
$\mathrm{Ca}$ & 219.60 \\
$\mathrm{Al}$ & 120.00 \\
$\mathrm{Mg}$ & 112.50 \\
$\mathrm{Fe}$ & 100.30 \\
$\mathrm{Na}$ & 34.62 \\
$\mathrm{Mn}$ & 32.84 \\
$\mathrm{~K}$ & 11.14 \\
$\mathrm{Zn}$ & 6.704 \\
$\mathrm{Ni}$ & 1.651 \\
$\mathrm{Co}$ & 1.623 \\
$\mathrm{Sr}$ & 0.612 \\
$\mathrm{Ba}$ & 0.204 \\
$\mathrm{Cu}$ & 0.049 \\
\hline
\end{tabular}

content, indicating that the mine water was influenced by dolomitic mineralogy (Madzivire et al., 2009). Moreover, it was noticed that the composition of AMD was varying every time a new batch of water was delivered on-site from the source due to seasonal and other fluctuation. The treatment of AMD with fly ash takes advantage of the $\mathrm{CaO}$ found in fly ash, which is necessary for the neutralization of the mine water and the removal of sulfate and other pollutants present in AMD.

The XRF results of the two sources of fly ash are shown in Table 3. Both fly ashes were Class F, which was indicated by the sum of the total aluminum, silicon, and iron oxides in the ash found greater than $70 \%$ (ASTM C618, 2005).

Table 3 showed that both sources of ash had an elemental composition that was typical for South African fly ash (Ayanda et al., 2012; Nyale et al., 2013) and also that fly ash A had $1.23 \%$ higher $\mathrm{CaO}$ content than fly ash $\mathrm{B}$. It is expected that, $\mathrm{CaO}$ content would have an impact in the treatment of AMD with fly ash. The variation of fly ash composition per batch delivered on-site was not very significant unlike that for AMD, and was consistent with previous analyses of Mpumalanga fly ash from various coal-fired power stations (Ayanda et al., 2012).

\subsection{Treatment of acid mine drainage results}

The proof of concept of the $1500 \mathrm{~L}$ was performed using the optimum conditions obtained at $80 \mathrm{~L}$ by Madzivire et al. (2015). Table 4 shows the composition of raw and treated water obtained using the $1500 \mathrm{~L}$ pilot plant with liquid to solid ratio of 5:1 (AMD: fly ash), $2.5 \mathrm{~kg}$ of lime, and $3.6 \mathrm{~kg}$ of $\mathrm{Al}(\mathrm{OH})_{3}$ after $180 \mathrm{~min}$ of experimental time (see section 2.2.). The ICP-OES and IC results are presented in Table 4.

Table 3

Elemental composition of fly ash using XRF (mass percent).

\begin{tabular}{lll}
\hline Element & Fly ash A (\%) & Fly ash B (\%) \\
\hline $\mathrm{SiO}_{2}$ & 54.51 & 58.19 \\
$\mathrm{Al}_{2} \mathrm{O}_{3}$ & 30.20 & 29.50 \\
$\mathrm{Fe}_{2} \mathrm{O}_{3}$ & 4.24 & 3.51 \\
$\mathrm{CaO}$ & 6.03 & 4.66 \\
$\mathrm{TiO}_{2}$ & 1.68 & 1.61 \\
$\mathrm{MgO}$ & 1.60 & 1.05 \\
$\mathrm{~K}_{2} \mathrm{O}$ & 0.83 & 0.78 \\
$\mathrm{P}_{2} \mathrm{O}_{5}$ & 0.56 & 0.35 \\
$\mathrm{MnO}$ & 0.04 & 0.03 \\
$\mathrm{Cr}_{2} \mathrm{O}_{3}$ & 0.03 & 0.03 \\
$\mathrm{Na}_{2} \mathrm{O}$ & 0.26 & 0.27 \\
$\mathrm{~V}_{2} \mathrm{O}_{5}$ & 0.02 & 0.02 \\
$\mathrm{Total}$ & 100 & 100 \\
\hline
\end{tabular}

Raw AMD had a pH of 2.26. The relative quantities of soluble bases $(\mathrm{CaO}, \mathrm{MgO})$ in fly ash and hydrolysable constituents in AMD dictated whether the final solution at a given contact time will be acidic or basic. Based on the results in Table 4 the increase of solution $\mathrm{pH}$ with contact time caused the removal of the metal ions mainly by precipitation, coprecipitation, and adsorption (Gitari et al., 2008).

The concentration of sulfate, $\mathrm{Al}, \mathrm{Ca}$, and $\mathrm{Fe}$ was decreased to well below that of the raw AMD after $30 \mathrm{~min}$, before the addition of $\mathrm{Al}$ $(\mathrm{OH})_{3}$. Therefore, it is noteworthy that the concentration of most contaminants in the treated AMD was significantly lower compared to the raw AMD, and thus extending the treatment time was not needed.

Ions such as $\mathrm{Cu}$, Co, and $\mathrm{Ti}$ showed approximately 100\% removal since they were only detected in the raw AMD and not in the treated AMD. Low traces of $\mathrm{Sr}(7.16 \mathrm{mg} / \mathrm{L})$, As $(0.55 \mathrm{mg} / \mathrm{L})$, Mo $(0.84 \mathrm{mg} / \mathrm{L})$, and P $(0.66 \mathrm{mg} / \mathrm{L})$ were detected in the treated water. These were the only contaminants leached from the fly ash during the treatment of AMD since they were only detected in the treated AMD and not in the raw AMD. Overall, $180 \mathrm{~min}$ of treatment resulted in the reduction of the concentration of $\mathrm{Si}$ and $\mathrm{Cd}$ or complete removal of $\mathrm{Cu}, \mathrm{Zn}, \mathrm{Co}, \mathrm{Ni}, \mathrm{Se}, \mathrm{Li}$, $\mathrm{K}$, and $\mathrm{Ti}$ in the AMD. Therefore, the addition of $\mathrm{Al}(\mathrm{OH})_{3}$ assisted further to reduce the concentration of these contaminants. However, the lowest concentration of $\mathrm{Ca}, \mathrm{Mo}, \mathrm{Cr}, \mathrm{Pb}, \mathrm{Al}, \mathrm{Mg}, \mathrm{Fe}, \mathrm{Na}$, and sulfate were recorded after $90,60,90,120,150,60,150,60$, and $150 \mathrm{~min}$ of treatment respectively, before $\mathrm{Al}(\mathrm{OH})_{3}$ addition. Thus $\mathrm{Al}(\mathrm{OH})_{3}$ addition was not strictly necessary depending upon the required target water quality.

The chemical reactions that took place during the first $30 \mathrm{~min}$ at a $\mathrm{pH}$ of 10.5 in Table 4 were per our previous studies on this subject by Vadapalli et al. (2008); Madzivire et al. (2010); and Madzivire et al. (2015), who reported on the removal of pollutants in AMD when treated with fly ash and lime concerning $\mathrm{pH}$ variation. It was demonstrated that $\mathrm{Mg}$ concentration decreased to below the detectable limit when the $\mathrm{pH}$ was in the range of 9.5-11.5 due to the formation of $\mathrm{Mg}$ $(\mathrm{OH})_{2}$. Mn precipitated as $\mathrm{Mn}(\mathrm{OH})_{2}$ at $\mathrm{pH}$ 8.5-9.5. Cu precipitated as cupric and cuprous ferrite and could be absorbed on the surface of fly ash at $\mathrm{pH}$ values between 5 and 6 . At $\mathrm{pH}$ between 6 and $7, \mathrm{Zn}$ coprecipitated with $\mathrm{Si}$ that was solubilized from fly ash and formed willemite. The $\mathrm{Ca}^{2+}$ ions from fly ash or lime combine with sulfate to form gypsum leading to the removal of sulfate. Oxidation of $\mathrm{Fe}^{2+}$ occurred in the presence of oxygen and was maximum at $\mathrm{pH}$ 5-7 with the hydrolysis of the resulting $\mathrm{Fe}^{3+}$ resulting in the formation of amorphous ferric hydroxides, which adsorbed more of the sulfate. In this $\mathrm{pH}$ range, a significant decrease in sulfate concentration was observed. The formation of amorphous aluminum hydroxide at a $\mathrm{pH}$ greater than 4 was also believed to contribute to decreased sulfate content and was enhanced by the formation of gypsum. At a pH greater than 9 a mineral phase known as ettringite formed and mainly contributed to the decrease in sulfate concentrations.

The $1500 \mathrm{~L}$ pilot plant showed high performance in pollutant removal compared to the $80 \mathrm{~L}$ pilot plant. For example, the sulfate removal in the treatment of mine water using $1500 \mathrm{~L}$ (AMD, lime and fly ash, with no $\mathrm{Al}(\mathrm{OH})_{3}$ ), or at $80 \mathrm{~L}$ (AMD, lime, fly ash and $\mathrm{Al}(\mathrm{OH})_{3}$ ) pilot plant after $150 \mathrm{~min}$ of experimental time was $98.5 \%$ or $66.7 \%$ respectively. These results demonstrated that the kinetics of the removal of sulfate ions from AMD through the formation of ettringite and gypsum was enhanced not only by the addition of fly ash, lime, or $\mathrm{Al}(\mathrm{OH})_{3}$ to AMD but also by the effective mixing achieved by the three jet loop reactors used in the designed $1500 \mathrm{~L}$ pilot plant. In the mixing tank, the solution (of AMD, fly ash, and lime) was mixed at a speed of $50 \mathrm{rpm}$ and then pumped at a pressure of 4.5 bar to the jet loop reactors. In the jet loop reactors, impingement and cavitation occurred. Impingement is the violent contact of the mixture (AMD + fly ash + lime + aluminum hydroxide) coming from two directions (within the orifices). Cavitation is the formation, growth, and collapse of bubbles (cavity) within a liquid because of local pressure pulsations. The liquid that contains vaporous bubbles, experiences a consistent pressure reduction which 
Table 4

Composition of raw and treated AMD after 180 min of treatment using the jet loop reactor $1500 \mathrm{~L}$ pilot plant.

\begin{tabular}{|c|c|c|c|c|c|c|c|c|c|}
\hline \multirow[t]{2}{*}{ Parameter } & \multirow[t]{2}{*}{ Raw AMD } & \multicolumn{6}{|c|}{ Treated AMD (min) } & \multicolumn{2}{|l|}{ TWQR } \\
\hline & & 30 & 60 & 90 & 120 & 150 & 180 & irrigation & domestic \\
\hline $\mathrm{pH}$ & 2.26 & 10.1 & 9.9 & 9.9 & 9.7 & 10.5 & 8.8 & $6.5-8.4$ & $6-9$ \\
\hline \multicolumn{10}{|c|}{ Element (mg/L) } \\
\hline Sulfate & 5680.33 & 92.77 & 90.99 & 85.01 & 92.28 & 83.37 & 87.27 & NL & $0-500$ \\
\hline $\mathrm{Al}$ & 1862.51 & 26.07 & 21.20 & 10.18 & 2.68 & 1.30 & 13.37 & $0-5$ & $0-0.15$ \\
\hline $\mathrm{Ca}$ & 1694.55 & 305.13 & 250.56 & 228.48 & 253.02 & 248.77 & 242.77 & NL & $0-32$ \\
\hline $\mathrm{Fe}$ & 1377.74 & 1.38 & 0.43 & 0.77 & 0.11 & 0.08 & 0.54 & $0-5$ & $0-0.1$ \\
\hline $\mathrm{Mg}$ & 765.62 & 0.33 & 0.04 & 0.07 & 0.07 & 0.27 & 0.05 & NL & $0-30$ \\
\hline $\mathrm{Si}$ & 482.22 & 16.96 & 17.03 & 17.53 & 17.54 & 21.26 & 16.60 & NL & NA \\
\hline $\mathrm{Na}$ & 463.35 & 73.07 & 70.02 & 71.46 & 71.94 & 71.26 & 86.46 & $0-70$ & $0-100$ \\
\hline Mn & 224.44 & 0.01 & ND & 0.01 & 0.06 & 0.07 & 0.05 & $0-0.02$ & $0-0.05$ \\
\hline $\mathrm{Zn}$ & 154.59 & 0.57 & 0.08 & 0.18 & ND & ND & ND & $0-1$ & $0-3$ \\
\hline $\mathrm{Ni}$ & 79.62 & 0.64 & 0.47 & 0.48 & 0.89 & 0.39 & ND & $0-0.2$ & NA \\
\hline $\mathrm{K}$ & 51.27 & 3.49 & ND & ND & ND & ND & ND & NL & $0-50$ \\
\hline Co & 30.55 & ND & ND & ND & ND & ND & ND & $0-0.05$ & NA \\
\hline $\mathrm{Cu}$ & 23.74 & ND & ND & ND & ND & ND & ND & $0-0.2$ & $0-1$ \\
\hline $\mathrm{Pb}$ & 16.55 & 1.18 & 0.70 & 1.07 & 0.34 & 1.66 & 1.49 & $0-0.2$ & $0-0.01$ \\
\hline $\mathrm{Ti}$ & 4.80 & ND & ND & ND & ND & ND & ND & NA & $0-0.01$ \\
\hline $\mathrm{Sr}$ & 3.43 & 4.90 & 4.08 & 6.33 & 7.52 & 9.04 & 7.16 & NL & NA \\
\hline $\mathrm{Cd}$ & 1.50 & 0.07 & 0.06 & 0.08 & 0.04 & 0.08 & 0.03 & $0-10$ & $0-5$ \\
\hline $\mathrm{Cr}$ & 1.03 & 1.01 & 1.78 & 0.98 & 1.28 & 1.12 & 1.27 & $0-0.1$ & $0-0.05$ \\
\hline As & ND & 0.36 & 0.48 & 1.41 & 0.11 & 0.93 & 0.55 & $0-0.1$ & $0-0.001$ \\
\hline Mo & ND & 1.26 & 0.35 & 0.63 & 1.31 & 1.16 & 0.84 & $0-0.01$ & $0-0.07$ \\
\hline $\mathrm{Se}$ & ND & ND & ND & ND & ND & 0.80 & ND & $0-0.02$ & $0-0.02$ \\
\hline $\mathrm{P}$ & ND & 1.39 & 1.16 & 0.36 & 0.46 & 0.01 & 0.66 & $0-0.2$ & NA \\
\hline $\mathrm{Li}$ & ND & 0.82 & 0.61 & 0.67 & 0.69 & 0.56 & ND & $0-2.5$ & NA \\
\hline
\end{tabular}

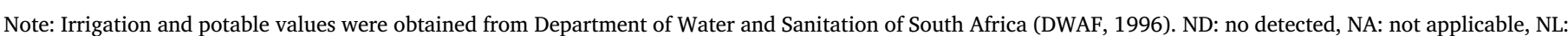
no limits specified, min: minutes. TWQR: target water quality range. The units for parameters are $\mathrm{mg} / \mathrm{L}$, except $\mathrm{pH}$, which is unitless.

increases the size (growth) of bubbles and their eventual collapse (implosion) at a critical magnitude of pressure (Badmus et al. 2018). At this stage, the critical pressure is lower or very close to the liquid specific saturated vapor pressure. The implosion of bubbles is accompanied by local destruction of chemical bonds, hydraulic shock, high temperature and pressure for a short period in the trapped vapor. This condition is adequate for rupture of biological or organic structures, and dissolution of soluble mineral phases in fly ash that enhanced supersaturated conditions in the aqueous phase, causing secondary mineral precipitation, as well as splitting of water molecules into $\mathrm{OH}$ and $\mathrm{H}$ radicals, which could promote redox reactions (Badmus et al., 2018). This phenomenon of supersaturation and redox reaction conditions enhanced the effect of high energy mixing, increased reaction rates, and improved the quality of the recovered water.

Based on the observations made from the results in Table 4; the addition of $\mathrm{Al}(\mathrm{OH})_{3}$ was not significant in the removal of pollutants in AMD because the $1500 \mathrm{~L}$ pilot plant worked well without it. Therefore, more focus was given to the effect of the amount of fly ash, and lime for $\mathrm{pH}$ and sulfate removal during the treatment of AMD.

\subsection{Optimization of the amount of fly ash and lime}

A liquid to solid ratio of 3:1 was used by Petrik et al. (2003) and Vadapalli et al. (2008) in order to raise the $\mathrm{pH}$ to greater than 11 and enhance the removal of sulfate and other pollutants in mine water. This resulted in a high volume of solid residue. However, Madzivire et al. (2015) used a liquid to solid ratio of 5:1 and 6:1 in the treatment of circumneutral mine drainage ( $\mathrm{pH}$ of 8 ) but these ratios could not bring the $\mathrm{pH}$ to greater than 11 using FA only without the addition of chemical reagents. Therefore, the present study investigated a liquid to solid ratios of $5: 1,6: 1$, and $7: 1$. The $\mathrm{pH}$ trends obtained during the treatment of AMD with fly ash without lime is depicted in Fig. 3.

Fig. 3 demonstrated that despite the small difference in $\mathrm{CaO}$ content in the two sources of fly ash used to treat AMD, the $\mathrm{pH}$ obtained was almost similar for every ratio of liquid to solid used after $60 \mathrm{~min}$ of mixing; even though the $\mathrm{pH}$ obtained using fly ash $\mathrm{B}$ was higher than that of fly ash A. This could be attributed to the particle size difference of these sources of fly ash. Fly ash enriched with fines was more efficient in increasing the $\mathrm{pH}$ from AMD (Vadapalli et al., 2007). According to Fig. 3 the ratios of 5:1, 6:1, and 7:1 liquid to solid could neutralize the AMD but could not increase the $\mathrm{pH}$ to greater than 11 after mixing for $60 \mathrm{~min}$.

The removal of sulfate in AMD occurs through the precipitation of $\mathrm{Ca}$ or $\mathrm{Al}$ and $\mathrm{Fe}$ in the form of gypsum or ettringite. Gypsum forms at any $\mathrm{pH}$ while ettringite forms at $\mathrm{pH}$ in the range of 11.5-12.5 (Madzivire et al., 2010). Therefore, the investigation of the minimum amount of lime to be added to the mixture of AMD and fly ash (L/S ratio of $6: 1$ ) to raise the $\mathrm{pH}$ to greater than 11 was carried out.

As shown in Fig. 4, the addition of $0.1 \%$ or $0.15 \%$ of lime to either fly ash A or fly ash B (L/S ratio of 6:1) increased the $\mathrm{pH}$ to greater than 11 , whereas the $\mathrm{w} / \mathrm{v} \%$ of lime to AMD of $0.05 \%$ did not raise the $\mathrm{pH}$ to above 11. Thus, it was observed that the higher the amount of lime added, the higher the final level of $\mathrm{pH}$.

These results are better than those reported by Madzivire et al. (2015) using an $80 \mathrm{~L}$ pilot plant where higher quantities of lime were added to the mixture of mine water and fly ash. This could be attributed to the effect of enhanced mixing speed and reaction rate resulting in improved product water at $1500 \mathrm{~L}$ pilot plant with three jet loop reactors and a mixing tank incorporated into the treatment system.

Table 5 shows the results of sulfate concentration when AMD was treated with fly ash only and with fly ash and lime.

As shown in Table 5 (fly ash only), acceptable sulfate removal from AMD (48.7\% and 48.2\%) was achieved using the 6:1 ratio with fly ash $\mathrm{A}$ and fly ash $\mathrm{B}$, respectively. The removal of sulfate was attributed to the free $\mathrm{CaO}$ present in fly ash that precipitated sulfate in the form of gypsum according to equations (5) and (6).

$\mathrm{CaO}+\mathrm{H}_{2} \mathrm{O} \rightarrow \mathrm{Ca}^{2+}+2 \mathrm{OH}$

$\mathrm{Ca}^{2+}++2 \mathrm{H}_{2} \mathrm{O} \leftrightarrow \mathrm{CaSO}_{4} \cdot 2 \mathrm{H}_{2} \mathrm{O}$

However, the remaining sulfate concentration was still outside the 

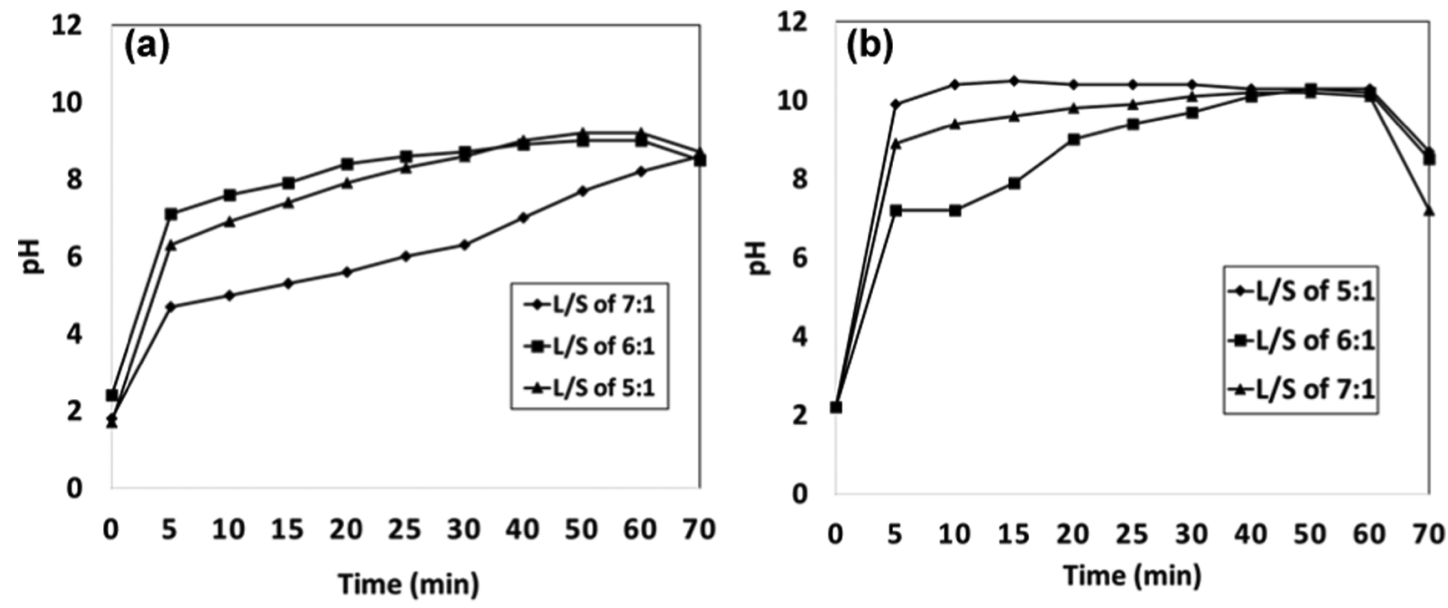

Fig. 3. Effect of $\mathrm{pH}$ with time from various liquid to solid ratios using (a) fly ash A and (b) fly ash B in the treatment of AMD.

TWQR. Based on these results, the optimum ratio of liquid to solids was chosen as 6:1 because the $\mathrm{pH}$ of AMD obtained was high enough and $70 \%$ of water was recovered. The liquid to solid ratio of 5:1 resulted in only $547 \mathrm{~kg}(50 \%)$ of water recovery. This was attributed to high water retention in the fly ash solid residue.

The results in Table 5 (fly ash + lime) have shown that only a small quantity of lime was required to raise the $\mathrm{pH}$ to greater than 11 . The $\mathrm{pH}$ increase achieved by additional $\mathrm{CaO}$ facilitated the precipitation of sulfate in the form of gypsum as shown in equations (4) and (5), and the formation of ettringite due to $\mathrm{Al}$ and Fe content in AMD and fly ash. The presence of $\mathrm{Fe}$ and $\mathrm{Al}$ in the raw AMD and fly ash composition were very significant in the treatment of mine water. These two metals precipitated in the form of oxyhydroxides and oxyhydroxysulfates which tended to adsorb sulfate leading to increase sulfate removal (Rose and Ghazi, 1997). Although the variations in the chemical composition of the fly ash and AMD supplied influenced the neutralization reaction time, the jet loop reactor pilot plant used very little chemical reagents ( $1 \mathrm{~kg}$ of lime per $1000 \mathrm{~L}$ of AMD) and achieved good quality and high water recovery of about $66.6 \%(728.6 \mathrm{~kg})$. This could be enhanced by actively dewatering the slurry instead of just using gravity settling to separate the liquid from the solids as was done in this study.

The final concentration of $\mathrm{SO}_{4}{ }^{2-}$ was within the limits set for Class II (400-600 mg/L) or below (see Table 4) drinking water guidelines (DWAF, 1996). The addition of a small amount of lime was important because the treatment of AMD with fly ash only could not bring the water to within the specification for irrigation water quality. The treated water could be used in the agriculture and process industry. The
Table 5

Sulfate concentration of raw AMD and AMD treated either with fly ash only or with fly ash and lime.

\begin{tabular}{llllll}
\hline \multicolumn{2}{l}{ Fly ash only } & \multicolumn{5}{c}{ Fly ash + lime } \\
\hline L/S & $\begin{array}{l}\text { Fly ash A } \\
(\mathrm{mg} / \mathrm{L})\end{array}$ & $\begin{array}{l}\text { Fly ash B } \\
(\mathrm{mg} / \mathrm{L})\end{array}$ & W/V\% & $\begin{array}{l}\text { Fly ash A } \\
(\mathrm{mg} / \mathrm{L})\end{array}$ & $\begin{array}{l}\text { Fly ash B } \\
(\mathrm{mg} / \mathrm{L})\end{array}$ \\
\hline Raw AMD & 2680 & 2680 & $\begin{array}{l}\text { Raw } \\
\text { AMD }\end{array}$ & 2006.28 & 2006.28 \\
$7: 1$ & 1534.62 & 1444.18 & 0.05 & 541.32 & 508.96 \\
$6: 1$ & 1397 & 1389.22 & 0.1 & 535.99 & 530.82 \\
$5: 1$ & 1375.83 & 1464.54 & 0.15 & 549.22 & 508.83 \\
\hline
\end{tabular}

Note: L/S stands for a liquid to solid ratio; W/V\% stands for weight to volume percent of lime to AMD.

Table 6

Product streams composition of the $1500 \mathrm{~L}$ batch pilot plant.

\begin{tabular}{llc}
\hline Output & Element & Mass (kg) \\
\hline M3 & Treated water & 728.56 \\
M4 & Solid residue (slurry) & 571.54 \\
& Total & 1286.85 \\
\hline
\end{tabular}
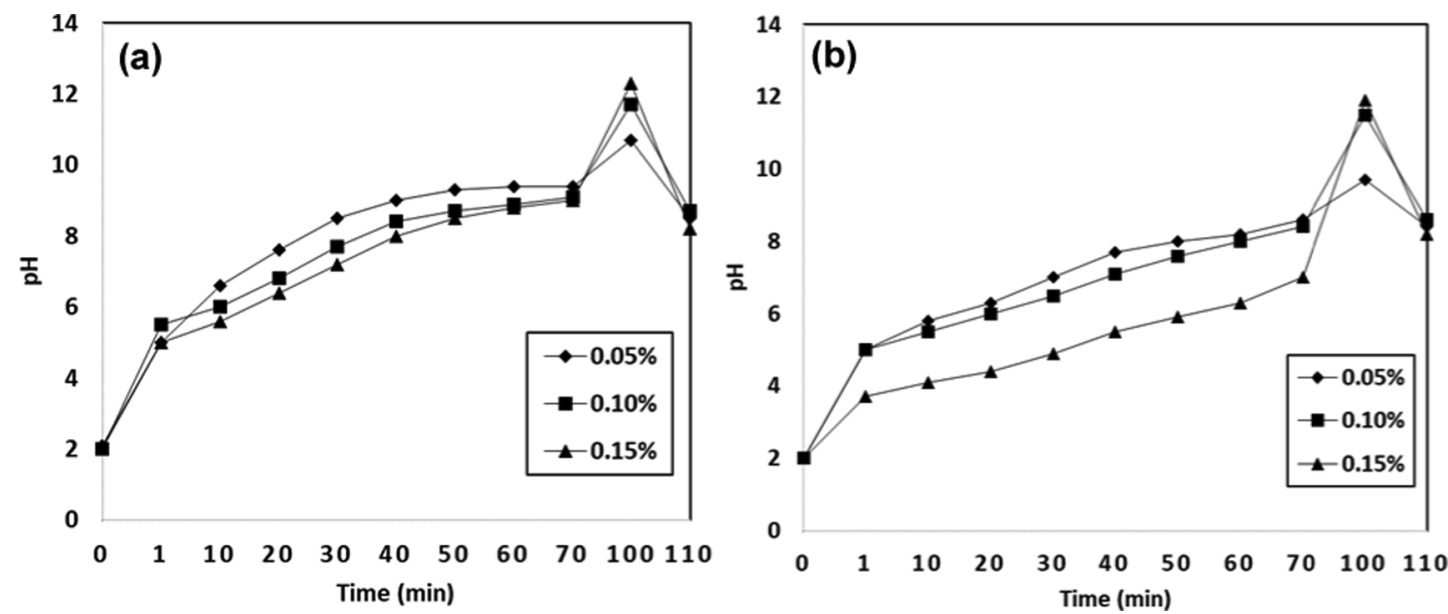

Fig. 4. Effect of $\mathrm{pH}$ with time during the treatment of AMD using (a) fly ash $\mathrm{B}$, and (b) fly ash $\mathrm{A}$ by adding various w/v\% ratios of lime to AMD. 
solid residue of this process could be used in many applications including as a paste for mine backfilling (Petrik et al., 2003).

\subsection{Mass balance}

The amount of recovered treated water and slurry are shown in Table 6. The amount of treated water was $67 \%$ of raw water and $571.54 \mathrm{~kg}$ of the slurry was formed. The moisture content in the slurry was $64 \%$. This meant that the slurry consisted of $365.78 \mathrm{~kg}$ of water and $205.76 \mathrm{~kg}$ of solids after gravity settling for 30 minutes, beyond this time period no further settling was observed.

Table 1 and Table 6 confirmed the assumption indicating that inputs equal to outputs during the AMD treatment process in terms of masses of solids and liquids. The active dewatering could increase the quantity of recovered treated water. The final slurry density depends entirely on the desired degree of dewatering required to achieve an appropriate slurry density for the transport of the residues to the potential backfill site or disposal or the geopolymer production unit.

\subsection{Energy balance}

The energy balance calculations showed that the velocity of the fluid was $3.457 \mathrm{~m} / \mathrm{s}$. The Reynold number of 47,776 indicated that the flow was turbulent within the pipe. The material of construction of the pipe was stainless steel $\left(\epsilon=2.5 \times 10^{-5}\right)$ and the surface roughness relative to the pipe diameter was $0.5 \times 10^{-3}$. Using the Moody chart, the Darcy friction factor was approximately 0.031 . The Fanning friction was equal to one-quarter of the Darcy factor. Therefore, the fanning friction was equivalent to $7.75 \times 10^{-3}$. The head loss, head loss due to friction, and head developed by the pump were $0.548,11.534$, and $13.051 \mathrm{~m}$ respectively. Then the fluid, shaft, and electrical power were $0.951,2.377$, and $2.655 \mathrm{~kW}$ respectively.

The amount of energy released by the shaft was $2.377 \mathrm{~kW}$. However, the energy imparted to the flow of the fluid was $0.951 \mathrm{~kW}$. It was observed that the higher the pump's efficiency, the lower the energy imparted to the fluid by the pump. The mechanical energy of the shaft might have been transformed into heat because the energy balance principle stated that energy was conserved. The energy required to treat $1000 \mathrm{~L}$ of AMD with $200,2.5$, and $3.6 \mathrm{~kg}$ of fly ash, lime, and Al $(\mathrm{OH})_{3}$, respectively, was determined as $2.655 \mathrm{~kW}$ for pump 1 (see Fig. 2). These results indicated that the $1500 \mathrm{~L}$ batch pilot plant utilized only a small fraction of the pump capacity. Therefore, the centrifugal pump ( $15 \mathrm{~kW}$ capacity) used for the neutralization cycle was oversized and a smaller pump size would have been appropriate.

\section{Conclusion}

The feasibility and effectiveness of a $1500 \mathrm{~L}$ jet loop reactor pilot plant scaled up from $80 \mathrm{~L}$ for the treatment of AMD with fly ash were demonstrated in this study. Our results showed that a maximum $\mathrm{pH}$ of 9 can be achieved in the pilot plant by treating AMD with fly ash only, and a further increase of $\mathrm{pH}$ to 12 can be achieved by the addition of a small amount of lime. The high energy mixing within the pilot plant which is made up of impingement and cavitation generated supersaturated and redox reaction conditions that increased the reaction rates between $\mathrm{CaO}$ (in fly ash and extra lime) and AMD such that water of quality can be achieved.

This study has demonstrated that $98.4 \%$ sulfate can be removed alongside with most of the toxic metals after $30 \mathrm{~min}$ of contact time during the treatment of AMD with fly ash at the liquid to solid ratio of $5: 1$ and $0.25 \%(\mathrm{w} / \mathrm{v} \%)$ of lime in the pilot plant consisting of three jet loop reactors in parallel. The optimum treatment condition was shown to be AMD: fly ash of $6: 1$ and the $w / v \%$ of lime to AMD was $0.1 \%$.

It can be shown using a material balance that for feed materials consisting of $3.6 \mathrm{~kg}, 2.5 \mathrm{~kg}, 200 \mathrm{~kg}$, and $1094 \mathrm{~kg}(1000 \mathrm{~L})$ of $\mathrm{Al}(\mathrm{OH})_{3}$, lime, FA, and AMD respectively, a product consisting of $66.6 \%$ of treated clear water can be obtained in $30 \mathrm{~min}$ by settling. The water in the recovered sludge which constitutes $64 \%$ could be used to transport the slurry.

Therefore, this study showed that jet loop reactor pilot plant can be used to treat AMD with coal fly ash to produce clear water that meets South African agricultural standards while producing a spent fly ash slurry suitable for filling abandoned mines or conversion to geopolymer thereby striving at attain a circular economy in the coal mining and energy generation industries through beneficiation of the two waste streams which occur in close proximity.

The treated water may thereafter be used for agricultural or industrial purposes or may be further treated to be made potable by correcting $\mathrm{pH}$ and removing trace elements by ion-exchange resins or zeolite adsorption. The application of this pilot process may lead to the achievement of zero effluent in mines operations. The residue from the process may be suited for backfilling of mine voids to prevent further acid mine drainage formation, thereby offering a cradle-to-cradle solution.

\section{CRediT authorship contribution statement}

Rosicky Methode Kalombe: Methodology, Validation, Investigation, Visualization, Project administration. Tunde Victor Ojumu: Methodology, Validation, Investigation, Supervision. Vinny Ndjate Katambwe: Investigation. Michael Nzadi: Investigation. Denzil Bent: Investigation. George Nieuwouldt: Resources. Godfrey Madzivire: Methodology. John Kevern: . Leslie Felicia Petrik: Validation, Funding acquisition, Investigation, Supervision.

\section{Declaration of Competing Interest}

The authors declared that there is no conflict of interest.

\section{Acknowledgments}

The authors acknowledge the financial support provided by the Water Research Commission (Grant number: K5/2129), Eskom (Grant number: 45026954595), and Technology Innovation Agency (Grant number: UWC011-TSF).

\section{Appendix A. Supplementary material}

Supplementary data to this article can be found online at https:// doi.org/10.1016/j.mineng.2020.106611.

\section{References}

ASTM C-618, American Society for Testing and Materials, 2005. Standard speciation for fly ash and raw or calcined natural pozzolan for uses as a mineral admixture in Portland cement concrete. American Society for Testing and Materials, Philadelphia, Pennsylvania.

Ayanda, O.S., Olalekan, S.F., Folahan, A.A., Bhekumusa, J.X., 2012. Characterization of fly ash generated from matla power station in Mpumalanga, South Africa. E-J. Chem. 9 (4), 1788-1795. https://doi.org/10.1155/2012/451801.

Badmus, K.O., Jimoh, O.T., Massima, E., Petrik, L., 2018. Treatment of persistent organic pollutants in wastewater using hydrodynamic cavitation in synergy with advanced oxidation process. Environ. Sci. Pollut. Res. 25 (8), 7299-7314. https://doi.org/10. 1007/s11356-017-1171-Z.

Blissett, R.S., Rowson, N.A., 2012. A review of the multi-component utilisation of coal fly ash. Fuel 97, 1-23. https://doi.org/10.1016/j.fuel.2012.03.024.

Brodkey, R.S., Hershey, H.C., 1988. Transport Phenomena: A Unified Approach. McGrawHill chemical engineering series, New York, United States of America.

Department of Water Affairs and Forestry, 1996. South African water quality, guidelines, second ed. Volume 1: domestic use. CSIR Environmental Services, Pretoria.

Felder, R.M., Rousseau, R.W., 2005. Elementary principles of chemical processes, Third Edition With Integrated Media, and Study Tools. John Wiley \& Sons, Inc. New Jersey. United States of America.

Gazea, B., Adam, K., Gazea, B., Adam, K., Kontopoulos, A., 1996. A review of passive systems for the treatment of acid mine drainage. J. Minerals Eng. 9 (1), 23-42. https://doi.org/10.1016/0892-6875(95)00129-8.

Gitari, M.W., Petrik, L.F., Etchebers, O., Key, D.L., Iwuoha, E., Okujeni, C., 2006. 
Treatment of acid mine drainage with fly ash: removal of major contaminants and trace elements. J. Environ. Sci. Health. Part A, Toxic/Hazard. Substances Environ. Eng. 41 (8), 1729-1747. https://doi.org/10.1080/10934520600754425.

Gitari, W.M., Petrik, L.F., Etchebers, O., Key, D.L., Okujeni, C., 2008. Utilization of fly ash for treatment of coal mines wastewater: solubility controls on major inorganic contaminants. Fuel 87 (12), 2450-2462.

Madzivire, G., Gitari, W.M., Vadapalli, V.R.K., Petrik, L.F., 2015. Jet loop reactor application for mine water treatment using fly ash, lime and aluminium hydroxide. Int. J. Environ. Sci. Technol. 12 (1), 173-182. https://doi.org/10.1007/s13762-0130417-7.

Madzivire, G., Petrik, L.F., Gitari, W.M., Ojumu, T.V., Balfour, G., 2010. Application of coal fly ash to circumneutral mine waters for the removal of sulphates as gypsum and ettringite. Miner. Eng. 23 (3), 252-257. https://doi.org/10.1016/j.mineng.2009.12. 004.

Madzivire, G., Petrik, L. F., Balfour, F., Vadapalli, V. R. K., and Ojumu, T. V., 2009. Role of $\mathrm{pH}$ on sulphate removal from circumneutral mine water using coal fly ash, no. October: 462-471.

Mushia, N.M., Ramoelo, A., Ayisi, K.K., 2016. The impact of the quality of coal mine stockpile soils on sustainable vegetation growth and productivity. Sustainability 2016, 8, 546. https://doi.org/10.3390/su8060546.

Musyoka, N. M., 2009. Hydrothermal synthesis and optimisation of zeolite Na-P1 from South African coal fly ash hydrothermal synthesis and optimisation of zeolite Na-P1 from South African Coal Fly Ash, no. May. Available at: https://www academia.edu/ 21453123/Hydrothermal_synthesis_and_optimisation_of_zeolite_Na-P1_from_South_ African_coal_fly_ash (accessed on December 13, 2019).

National Assembly Question No. 3383 Nw3776e, 2018, no. 3383. Department: Environmental Affairs. The Republic of South Africa. Available at: https://www. environment.gov.za/sites/default/files/parliamentary_updates/pq3383_tonsinash producedbyEskomandSasol.pdf (accessed on August 4, 2019).

Nyale, S.M., Omotola, B.O., Grant, D.B., Böke, N., Petrik, L.F., 2013. Synthesis an characterization of coal fly ash-based foamed geopolymer. Proc. Environ. Sci. 18,
722-730. https://doi.org/10.1016/j.proenv.2013.04.098.

Oberholster, P.J., Myburgh, J.G., Ashton, P.J., Botha, A.M., 2010. Responses of phytoplankton upon exposure to a mixture of acid mine drainage and high levels of nutrient pollution in Lake Loskop, South Africa. Ecotoxicol. Environ. Saf. 73 (3), 326-335. https://doi.org/10.1016/j.ecoenv.2009.08.011.

Petrik, L.F., White, R.A., Klink, M.J., Somerset, V.S., Burgers, C.L., Fey, M.V., 2003. Utilization of South African Fly Ash to Treat Acid Coal Mine Drainage, and Production of High Quality Zeolites from the Residual Solids. International Fly Ash Symposium 2.

Potgieter, J. H., Monama, P., Van Grieken, R., 2006. Comparison of limestone, dolomite and fly ash as pre-treatment agents for acid mine drainage 19, 454-462. https://doi. org/10.1016/j.mineng.2005.07.009.

Rose, S., Ghazi, A.M., 1997. Release of sorbed sulfate from iron oxyhydroxides precipitated from acid mine drainage associated with coal mining 31(7), 2136-2140. https://doi.org/10.1021/es960970f.

Sear, L.K.A., 2009. Coal-fired power station ash products and EU regulation. Coal Combust. Gasificat. Prod. 1, 63-66. https://doi.org/10.4177/CCGP-D-09-00008.1.

Somerset, V., Petrik, L., Klink, M., Etchebers, O., White, R., Key, D., Iwuoha, E., 2005 Acid mine drainage transformation of fly ash into zeolitic crystalline phases. Fresenius Environ. Bull. 14 (11), 1074-1076.

Vadapalli, V.R.K., Petrik, L., Fester, V., Slatter, P., Sery, G., 2007. Effect of Fly Ash particle size on its capacity to neutralize Acid Mine Drainage and influence on the rheological behaviour of residual solids. World of Coal Ash (WOCA).

Vadapalli, V.R.K., Klink, M.J., Etchebers, O., Petrik, L.F., Gitari, W., White, R.A., Key, D., Iwuoha, E., 2008. Neutralization of acid mine drainage using fly ash, and strength development of the resulting solid residues. S. Afr. J. Sci. 104 (7-8), 317-322.

Valente, T.M., Gomes, C.L., 2009. Occurrence, properties and pollution potential of environmental minerals in acid mine drainage. Sci. Total Environ. 407 (3), 1135-1152. https://doi.org/10.1016/j.scitotenv.2008.09.050.

Walas, S.M., 1990. Chemical Process Equipment: Selection and Design. Butterworth Heinemann Series in Chemical Engineering, Massachusetts United States of America. 